\title{
Complete atrioventricular block as an initial manifestation of recurred oral cavity cancer: a case report
}

\author{
Jae Yeong Cho, Kye Hun Kim ${ }^{*}$ (D) Hyukjin Park, Hyun Ju Yoon and Jong Chun Park
}

\begin{abstract}
Background: Intracardiac invasion of head and neck cancer is extremely rare. Here, we report a case of recurred oral cavity cancer presenting with complete atrioventricular (AV) block caused by cardiac metastasis.

Case presentation: A 70-year-old male presented with dizziness for 2 days. He had a history of oral cavity cancer a year ago, and the tumor was treated by surgical excision after induction chemotherapy and concurrent chemoradiation therapy. Electrocardiography showed complete AV block with ventricular escape rate of 43 beats per minute. Cardiac imaging revealed about $4.0 \times 2.0 \mathrm{~cm}$-sized mass invading interventricular septum and AV nodes and protruding into the right ventricle. Magenetic resonance imaging of head and neck demonstrated recurred mass in oral cavity and maxillary sinus. Fluorodeoxyglucose-positron emission tomography showed hypermetabolic lesion in both oral cavity and the heart around interventricular septum and atrioventricular node indicating recurred oral cavity cancer with cardiac metastasis. Permament pacemaker of DDD type was implanted for the symptomatic complete AV block, and palliative chemotherapy was initiated.
\end{abstract}

Conclusion: The present case demonstrated that oral cavity cancer can metastasize to the heart, and complete AV block may be an initial manifestation of the recurrence of extracardiac cancer with intracardiac invasion.

Keywords: Oral cancer, Recurrence, Metastasis, Atrioventricular block

\section{Background}

Head and neck cancer usually metastasize to lung, bone, and liver, but the invasion of intracardiac sturctures by head and neck cancer are extremely rare $[1,2]$. Here, we report a case of recurred oral cavity cancer presenting with complete atrioventricular (AV) block caused by cardiac metastasis including AV node. We perform this case report according to the CARE guideline and its methodology.

\section{Case presentation}

A 70-year-old male presented with dizziness for 2 days. He had a history of oral cavity cancer a year ago. Three cycles of induction chemotherapy with a combination of docetaxel $70 \mathrm{mg} / \mathrm{m}^{2} /$ day, cisplatin $75 \mathrm{mg} / \mathrm{m}^{2} /$ day, and 5 -fluorouracil $1000 \mathrm{mg} / \mathrm{m}^{2} /$ day (DCF) for 4 days at each

* Correspondence: cvkimkh@gmail.com

Department of Cardiovascular Medicine, Chonnam National University

Hospital, 42 Jebong-ro, Dong-gu, Gwangju 61469, South Korea cycle for 8 weeks and concurrent chemoradiation therapy (CCRT) with a total of 33 times of radiation (200 cGy per fraction at one time) and weekly cisplatin $30 \mathrm{mg} / \mathrm{m}^{2}$ for 8 more weeks were done. Follow-up paranasal sinus computed tomography showed decreased size of enhancing mass with necrotic change within anterior hard palate, with bony destruction of maxilla. Since only a partial response was obtained after CCRT, the tumor was treated by complete surgical excision. On histopathologic examination, the tumor was proved to be a differentiated squamous cell carcinoma. After surgical treatment, there was no definite evidence of recurrence for 6 months.

Electrocardigraphy (ECG) at current admission showed complete AV block with a ventricular rate of $43 / \mathrm{min}$ (Fig. 1). Echocardiography and chest computed tomography revealed about $4.0 \times 2.0 \mathrm{~cm}$-sized hypoechoic mass arising from the interventricular septum in the vicinity of AV node and protruding into the right ventricle (Fig. 2). Magnetic resonance imaging of head

(c) The Author(s). 2018 Open Access This article is distributed under the terms of the Creative Commons Attribution 4.0 International License (http://creativecommons.org/licenses/by/4.0/), which permits unrestricted use, distribution, and 


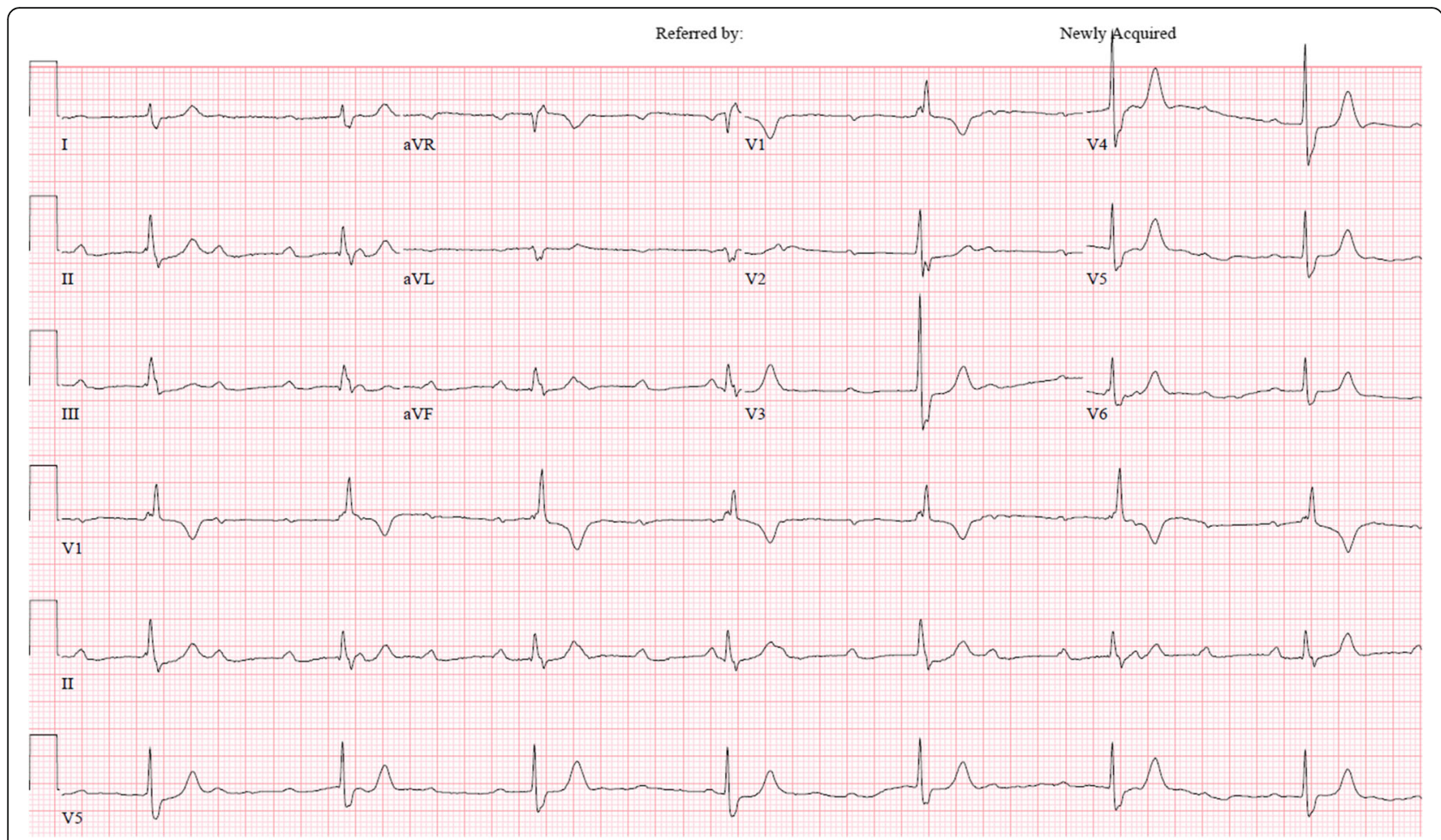

Fig. 1 Electrocardiography showed cocmplete atrioventricular block with ventricular escape rate of 43/min

and neck to evaluate the origin site of metastatic cardiac tumor revealed recurred mass in oral cavity and maxillary sinus (Fig. 3). Fluorodeoxyglucose-positron emission tomography (FDG-PET) showed hypermetabolic lesion in both oral cavity and the heart around interventricular septum and atrioventricular node (Fig. 4). Temporary pacemaker was inserted for complete AV block, but sinus rhythm was not restored despite 3 days of temporary pacing. A permament pacemaker of DDD type was implanted, and the patient was refered to oncology department for a palliative chemotherapy.

\section{Discussion and conclusions}

Although any type of tumor can metastasize to the heart, intracardiac invasion of head and neck cancer is rare. In patients with oral cavity cancer, distant metastasis to other organs and distant lymph nodes is generally a late event and usually represents an incurable disease [3]. The lung is the most common site of distant spread, and bone metastasis can also occur in case of other widespread metastatic disease $[4,5]$. However, distant metastasis to the heart by oral cavity cancer is extremely rare. In a study, oral cavity cancer had a invasion to the

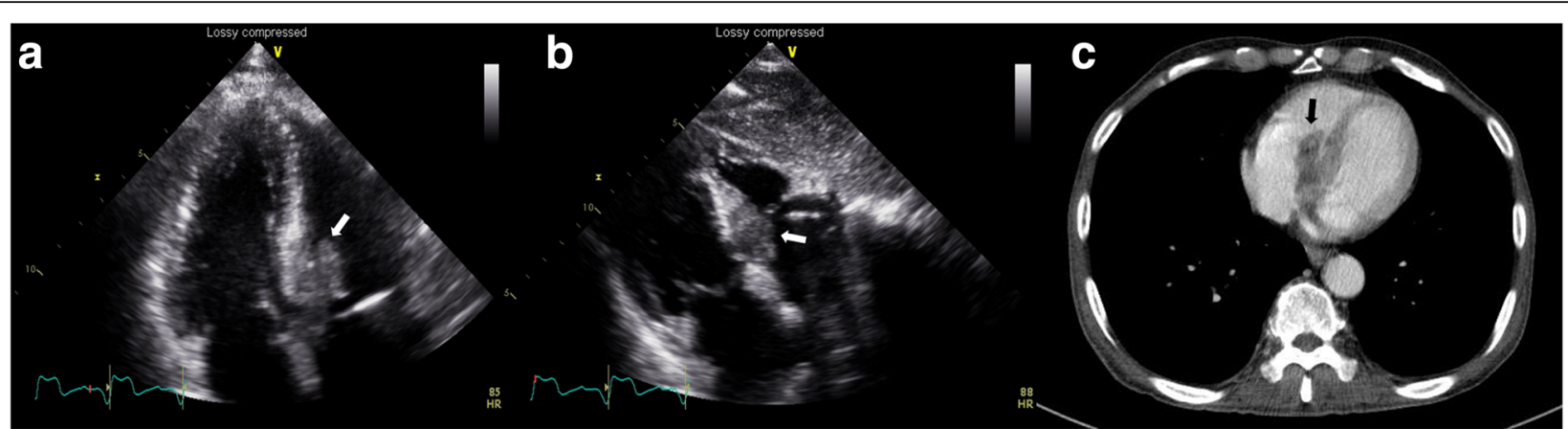

Fig. 2 Echocardiography ( $\mathbf{a}$ and $\mathbf{b}$ ) and chest computed tomography $(\mathbf{c})$ revealed about $4.0 \times 2.0 \mathrm{~cm}$-sized hypoechoic mass arising from the interventricular septum in the vicinity of AV node and protruding into the right ventricle 


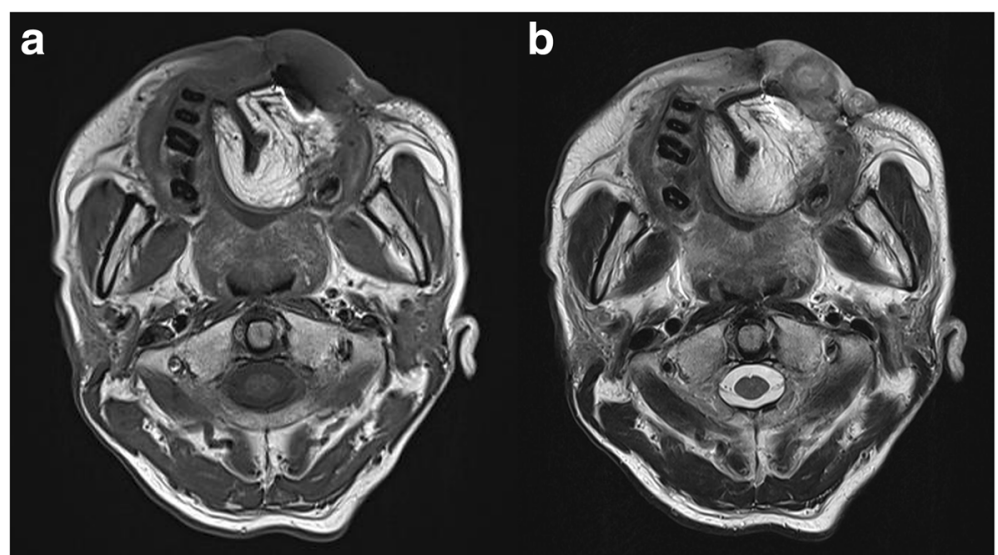

Fig. 3 Magnetic resonance imaging of head and neck showed recurred oral cavity cancer. Lobulated soft tissue mass with bony destruction involving anterior hard palate and both anterior alveolar ridge in the T1-weighted image (a) and T2-weighted image (b) was noted

heart in 4 out of 75 cases (5.3\%), while melanoma had 22 out of 79 (27.8\%), adenocarcinoma of lung had 97 out of $460(21.0 \%)$, and over all incidence were 662 out of 7289 (9.1\%) [6]. Apart from the lungs, screening for distant metastases is routinely not performed in initial staging of patients with head and neck cancer [4]. However, some studies have shown that FDG-PET is valuable in detecting distant metastasis in advanced head and neck cancer, suggesting a role for whole-body FDG-PET scanning for initial staging [7-9]. FDG-PET was also useful in the present case to demonstrate the recurrence of oral cavity cancer and intracardiac metastasis. To confirm the cardiac mass is originated from the metastasis from the recurred oral cavity cancer, histopathologic examinations by tissue biopsy from these 2 different sites or tissue characterizations by both cardiac MRI and head and neck MRI would be essential. However, intracardiac biopsy was not performed because of the patient's refusal and cardiac MRI could not be performed because the implanation of pacemaker was an obstacle for MRI. This issue would be the main limitation of this case. Considering clinical and imaging findings including FDG-PET, however, it is concluded that cardiac mass would be an metastatic lesion from the recurred oral cavity cancer.

In the present case, complete AV block on ECG was an initial clue for the recurrence of the previously treated oral cavity cancer and distant metastasis to the heart. Therefore, it is suggested that routine ECG may be incorporated into the surveillance for oral cavity cancer recurrence. In addition, further investigation is needed for the outcomes of AV block after chemotherapy for recurred cancer, which is totally unknown.

In conclusion, the present case demonstrated that oral cavity cancer can metastasize to the heart and complete AV block may be an initial manifestation of the recurrence of extracardiac cancer with intracardiac invasion. Therefore, distant metasis including cardiac metastasis should thoroughly evaluated by using multimodality imagings including echocardiography, computed tomography, magnetic resonance, and PET in patients with oral cavity cancer.

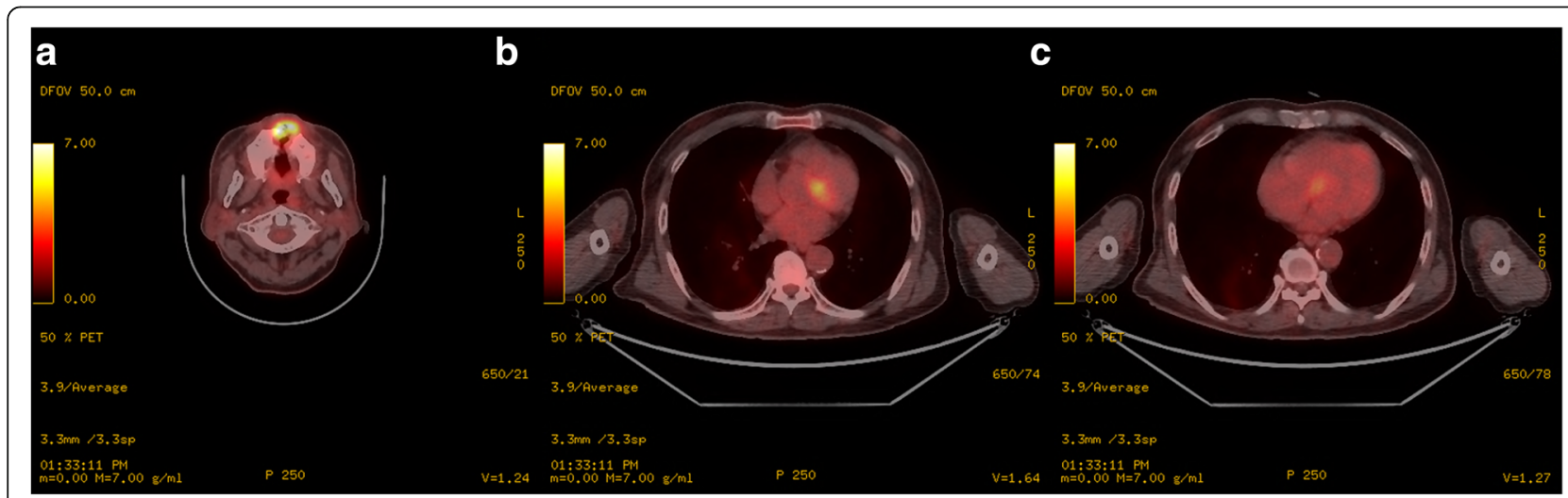

Fig. 4 Fluorodeoxyglucose-positron emission tomography showed hypermetabolic lesion in both oral cavity (a) and interventricular septum of the heart (b and $\mathbf{c})$ 


\section{Abbreviations}

AV: Atrioventricular; ECG: Electrocardiography; FDG: Fluorodeoxyglucose;

PET: Positron emission tomography

\section{Availability of data and materials}

All information supporting the conclusions of this article is presented in the article.

\section{Authors' contributions}

CJY, KKH, and PJC created the concept. CJY and KKH drafted the manuscript and performed echocardiography. PH and CJY provided image content. KKH and $\mathrm{YHJ}$ were involved in revising the manuscript critically. All authors gave final approval of the version to be published and agreed to be a accountable for all aspects of the work in ensuring that questions related to the accuracy or integrity of any part of the work are appropriately investigated and resolved.

\section{Ethics approval and consent to participate}

Not applicable.

\section{Consent for publication}

Written informed consent was obtained from the patient for publication of this case report and any accompanying images.

\section{Competing interests}

The authors declare that they have no competing interests.

\section{Publisher's Note}

Springer Nature remains neutral with regard to jurisdictional claims in published maps and institutional affiliations.

Received: 22 September 2017 Accepted: 26 June 2018

Published online: 09 July 2018

\section{References}

1. Ferlito A, Shaha AR, Silver CE, Rinaldo A, Mondin V. Incidence and sites of distant metastases from head and neck cancer. ORL J Otorhinolaryngol Relat Spec. 2001;63(4):202-7.

2. Leemans CR, Tiwari R, Nauta JJ, van der Waal I, Snow GB. Regional lymph node involvement and its significance in the development of distant metastases in head and neck carcinoma. Cancer. 1993;71(2):452-6.

3. Basu D, Siegel BA, McDonald DJ, Nussenbaum B. Detection of occult bone metastases from head and neck squamous cell carcinoma: impact of positron emission tomography computed tomography with fluorodeoxyglucose F 18. Arch Otolaryngol Head Neck Surg. 2007;133(8):801-5.

4. de Bree R, Deurloo EE, Snow GB, Leemans CR. Screening for distant metastases in patients with head and neck cancer. Laryngoscope. 2000;110(3 Pt 1):397-401

5. Brouwer J, Bree R, Hoekstra OS, Langendijk JA, Castelijns JA, Leemans CR. Screening for distant metastases in patients with head and neck cancer: what is the current clinical practice? Clin Otolaryngol. 2005;30(5):438-43.

6. Bussani R, De-Giorgio F, Abbate A, Silvestri F. Cardiac metastases. J Clin Pathol. 2007;60(1):27-34.

7. Wax MK, Myers LL, Gabalski EC, Husain S, Gona JM, Nabi H. Positron emission tomography in the evaluation of synchronous lung lesions in patients with untreated head and neck cancer. Arch Otolaryngol Head Neck Surg. 2002:128(6):703-7.

8. Perlow A, Bui C, Shreve P, Sundgren PC, Teknos TN, Mukherji SK. High incidence of chest malignancy detected by FDG PET in patients suspected of recurrent squamous cell carcinoma of the upper aerodigestive tract. J Comput Assist Tomogr. 2004;28(5):704-9.

9. Teknos TN, Rosenthal EL, Lee D, Taylor R, Marn CS. Positron emission tomography in the evaluation of stage III and IV head and neck cancer. Head Neck. 2001;23(12):1056-60.

\section{Ready to submit your research? Choose BMC and benefit from:}

- fast, convenient online submission

- thorough peer review by experienced researchers in your field

- rapid publication on acceptance

- support for research data, including large and complex data types

- gold Open Access which fosters wider collaboration and increased citations

- maximum visibility for your research: over $100 \mathrm{M}$ website views per year

At BMC, research is always in progress.

Learn more biomedcentral.com/submissions 